\title{
The 7th international conference on instrumental methods of analysis: modern trends and applications (IMA 2011)
}

\author{
Maria Ochsenkühn-Petropoulou • Panagiotis Kefalas • Nikolaos Kallithrakas-Kontos
}

Published online: 15 July 2012

(C) Springer-Verlag 2012

The 7th international conference "IMA 2011, Instrumental methods of analysis: modern trends and applications" was held from 18-22 September, 2011, in Chania (west Crete), which presents an excellent combination of cultural life, natural beauty (numerous beaches, gorges such as the renowned Samaria gorge, high mountains, biodiversity, etc.), a Venetian old town and many archaeological sites. The conference was held at the Conference Centre of the Mediterranean Agronomic Institute of Chania/Centre International de Hautes Etudes Agronomiques Méditerranéennes (MAICh/CIHEAM). This is a conference centre conceived with respect for the environment, situated $3 \mathrm{~km}$ from the centre of Chania on the campus of the institute.

IMA 2011 is the seventh conference in this series, which started in 1999 in Chalkidiki, Macedonia, Greece, under the chairmanship of Professor M. Ochsenkühn-Petropoulou and there has been a conference every 2 years since then organized by different other Hellenic academic institutions. IMA 2011 provided an excellent framework for the presentation of new

Published in the special paper collection Instrumental Methods of Analysis (IMA 2011) with guest editors Maria OchsenkuehnPetropoulou, Nikos Kallithrakas and Panagiotis Kefalas

M. Ochsenkühn-Petropoulou $(\square)$

Laboratory of Inorganic and Analytical Chemistry, National

Technical University, School of Chemical Engineering,

Iroon Polytechniou 9,

15773 Athens, Greece

e-mail: oxenki@central.ntua.gr

P. Kefalas

Mediterranean Agronomic Institute of Chania/

Centre International de Hautes Etudes Agronomiques

Méditerranéennes,

Alsyllio Agrokepiou, PO Box 85, 73100 Chania, Greece

e-mail: panos@maich.gr

N. Kallithrakas-Kontos

Technical University of Crete, University Campus,

73100 Chania, Greece

e-mail: kalli@mred.tuc.gr concepts, instruments, methods, systems and applications in the area of modern chemical analysis. Researchers and scientists from universities, research institutions, state organizations and industry were in attendance and presented their experiences in the current state of the art in the area of instrumental methods of analysis. Furthermore, IMA 2011 provided grounds for graduate and postgraduate students to disclose their projects, discuss scientific collaborations with other groups, as well as to explore employment opportunities. IMA 2011 was organized with the cooperation of two of the most important Cretan institutes: the Technical University of Crete (Analytical and Environmental Chemistry Laboratory) and the MAICh/CIHEAM. Co-organizers were other Hellenic academic analytical chemistry institutions actively involved in former IMA conferences.

The conference was opened by Professor Y. Phillis, Rector of the Technical University of Crete. Honorary prizes were awarded to Professor Elo Hansen, Denmark, and Professor Antonius Kettrup, Germany, for their top contributions in the field of analytical chemistry. Presentations were given in the fields of bioanalytics, speciation, sensors, materials science and nanomaterials, mass spectrometry, environmental analysis, chromatography, X-ray analysis and atomic absorption spectrometry over the 5 days of the conference. The scientific framework consisted of 14 sessions, 2 of which were held in parallel. Each session was introduced by a plenary lecture conducted by well-known invited scientists experienced in the respective fields from all over the world, for example, A. Sanz-Medel (Pulsed radiofrequency glow discharge time-of-flight mass spectrometry for isotopes, elements, molecules and nanostructured materials), R. Lobinski (High-resolution molecular mass spectrometry in the analysis of heteroatom-containing molecules), B. Michalke (Element speciation in neurodegenerative disease investigation-focus on manganese), G. Hieftje (New instruments for mass spectrometry), W. Lindner (Potential of chiral ion exchanger for chromatographic resolution of stereoisomers), and chaired by experts in instrumental methods of analysis. 
The conference was attended by more than 250 scientists from around 30 countries. The scientific program included, in addition to the 11 invited lectures mentioned previously, 61 oral presentations in parallel sessions and 2 poster sessions, each involving about 150 posters. During the conference, an exhibition of instrumentation, analytical supplies, scientific books and journals took place courtesy of the conference sponsors.

In addition to the science, the conference was complemented by a number of interesting and enjoyable social events, such as a Rethymno city tour, a Falasarna beach tour and a Knossos/Heraklion excursion, as well as a welcome party and the conference gala dinner. The program for IMA 2011, and further information, is still available at http://www.maich.gr/ima2011/index.html.

The next IMA conference, IMA 2013, will take place in Ioannina, Greece, organized by the University of Ioannina.

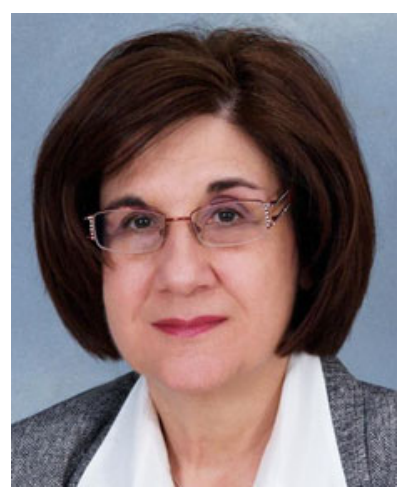

Maria Ochsenkühn-Petropoulou is a Professor at the School of Chemical Engineering of the National Technical University of Athens (NTUA) and head of the Instrumental Methods of Analysis Environment Group within the Laboratory of Inorganic and Analytical Chemistry. Since 1976, she has been Professor of Instrumental Methods of Analysis at the NTUA and teaches instrumental methods of analysis, environmental control and advanced inorganic chemistry to graduate and postgraduate students of the NTUA and has published ten educational books. Her research interests include speciation analysis; investigation into airborne particulate composition and particulates emitted from catalytic vehicles; trace-element analysis by voltammetric, spectrometric and hyphenated chromatographic techniques; utilization of industrial byproducts in the laboratory and on a pilot-plant scale; and the production and characterization of superconducting powders and coatings. She has published more than 220 scientific papers in international journals and conference proceedings and she has been the coordinator of more than 40 European and Greek research projects. She is the founder of the IMA International Conference series.

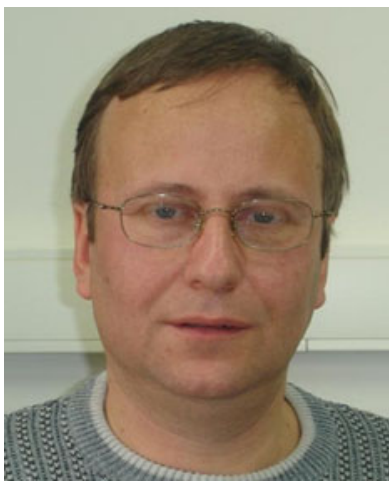

Nikolaos Kallithrakas-Kontos is a Professor at the Technical University of Crete (Chania) and the head of the Analytical and Environmental Chemistry Laboratory. His main research interests are in the area of X-ray analysis, improving the minimum detection limits of the method, total reflection X-ray fluorescence, speciation, surface analysis, archaeometry and environmental analysis. He has published 45 original papers and book chapters, with more than 300 citations, and he acts as a referee for many of the most important journals of his scientific area.

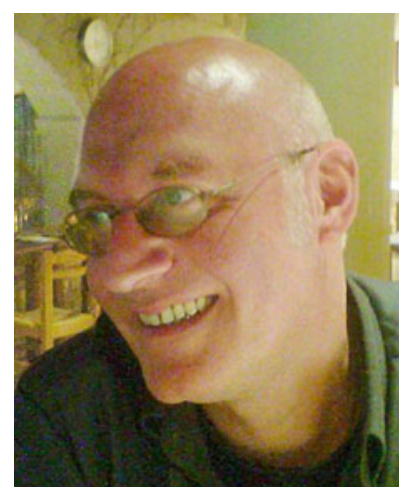

\section{Panagiotis Kefalas}

is presently coordinator of studies and research for the department of Food Quality and Chemistry of Natural Products with the Mediterranean Agronomic Institute of Chania/Centre International de Hautes Etudes Agronomiques Méditerranéennes (MAICh/ CIHEAM). His main interests are the isolation and identification of natural products, exploitation of agricultural waste, antioxidant activity and chemiluminescence, authentication, ESI fragmentation mechanisms and synthetic approaches to natural products. He currently has 90 peer-reviewed publications, 3 book chapters, and 1 EU patent on the isolation of high-purity oleuropein from the leaves of the olive tree. 